\title{
¿Participar para transformar? La experiencia de los Presupuestos Participativos en la provincia de Barcelona'
}

\author{
Ismael Blanco \\ Universitat Pompeu Fabra \\ ismael.blanco@upt.edu \\ Marta Ballester \\ Universitat de Barcelona \\ martaballesterfrago@hotmail.com
}

\begin{abstract}
Resumen
¿Qué cabe esperar de los procesos de participación ciudadana en las políticas públicas locales?, ¿Es razonable esperar transformaciones políticas significativas? En este artículo se identifican aquellas condiciones que, a nivel teórico, podemos prever que determinen la capacidad transformadora de la participación ciudadana. Esta discusión teórica da lugar a un marco de evaluación de las prácticas de participación que se aplica al análisis de las 11 experiencias vigentes de presupuestos participativos en la provincia de Barcelona. El análisis pone en evidencia los límites de este tipo de prácticas de participación, los cuales están relacionados con tres factores principales: su posición institucional periférica; el escaso margen de decisión que se concede a la ciudadaní; y la escasa movilización social. Sin embargo, los casos analizados obtienen buenos resultados en dos aspectos importantes: el impacto de las propuestas ciudadanas en la toma de decisiones públicas y la transformación de las actitudes políticas, técnicas y ciudadanas hacia la participación. El marco de evaluación propuesto nos ayuda a identificar ámbitos críticos de mejora de los procesos participativos y de fortalecimiento de su capacidad transformadora.
\end{abstract}

Palabras clave

Participación ciudadana, presupuestos participativos, políticas públicas locales, transformación política.

\section{Modification through participation? Participatory budgeting practice in Barcelona}

\begin{abstract}
What can we expect from citizen participation processes in local policymaking? Is it reasonable to expect significant political transformations? In this article, we identify the conditions that theoretically determine the transformation capacity of citizen participation. Such theoretical discussion gives place to a framework for the assessment of participative practices, which we use to analyse 11 cases of participatory budgeting in the province of Barcelona. The analysis puts in evidence the limits of this kind of participative practices, which are linked to three main factors: their peripheral institutional position; the scarce decision margin that is given to the citizens; and the lack of social mobilization. However, the cases analysed reach a good performance in two important aspects: the impact of citizens' proposals on public decision-taking and the transformation of the attitudes of local authorities, the public employees and the citizens themselves towards public participation. The assessment framework proposed helps us to identify critical aspects for the improvement and the strengthening of the transformation capacity of participative processes.
\end{abstract}

Key words

Citizen participation, participatory budgeting, local public policies, political transformation.

$1 \quad$ Este artículo es fruto del trabajo colectivo realizado en el marco del Grupo de Aprendizaje en Presupuestos Participativos promovido por la Oficina de Participación Ciudadana (OPC) del Área de Igualdad y Ciudadanía de la Diputación de Barcelona. Los autores del artículo quieren agradecer a los integrantes de este Grupo su participación activa, aportando valiosísimas informaciones y reflexiones de las que se alimenta este artículo. También quieren agradecer los comentarios críticos de Guida Obrador y de Laura Giménez (OPC), así como de los dos evaluadores anónimos. 


\section{INTRODUCCIÓN}

A lo largo de los últimos años, hemos asistido a una eclosión de experiencias de participación ciudadana en las políticas públicas, particularmente (aunque no exclusivamente) en el ámbito local. Sin duda, la elaboración participativa de las políticas locales continúa siendo la excepción y no la regla, aunque disponemos de evidencias empíricas que nos permiten constatar no sólo un incremento significativo de las prácticas locales de participación ciudadana, sino también una creciente preocupación por la innovación metodológica (Font, 2001; Del Pino y Colina, 2003).

Entre la gran diversidad de experiencias participativas impulsadas en estos últimos años, cabe destacar los denominados Presupuestos Participativos. Existen distintas razones para considerarlos como uno de los dispositivos participativos más emblemáticos: la gran proyección internacional que han adquirido las experiencias brasileñas; la incidencia directa de estos procesos participativos sobre las finanzas municipales; y el hecho que las propuestas formuladas por la ciudadanía en estos espacios participativos tengan impactos claros y tangibles, fácilmente observables en la configuración de los pueblos y ciudades.

En Brasil, se cuentan más de 200 experiencias de Presupuesto Participativo a nivel municipal (Avritzer y Navarro, 2003). Experiencias como las de Porto Alegre, Belo Horizonte o Recife, además, han servido como referente para muchas otras ciudades del Cono Sur. También en Europa empezaron a llegar las primeras experiencias de Presupuestos Participativos a finales de los años 90. Una investigación realizada en 2005 contaba por aquel entonces 55 experiencias en Europa, el 25\% de las cuales se estaban desarrollando en España (Sintomer et al., 2008). Ganuza y Gómez (2008) identificaron 22 casos en España con anterioridad a las elecciones municipales de 2007. En el estudio que aquí presentamos, identificamos 11 experiencias entre los 311 municipios de la provincia de Barcelona, algunas de las cuales, a pesar de ser vigentes, no habían sido detectadas por los estudios que acabamos de citar.

¿Qué cabe esperar de este tipo de prácticas de participación ciudadana? ¿Es razonable esperar de ellas efectos transformadores significativos? Creemos que en la literatura sobre mecanismos de participación ciudadana han predominado las visiones optimistas. Algunos, por ejemplo, han defendido la participación como un instrumento de combate a la desafección democrática (Dalton, 2004); otros han observado en este tipo de prácticas una oportunidad para contrarrestar la crisis del capital social (Putnam, 2002); también se ha argumentado la participación como vía de mejora de la eficiencia y la equidad las políticas públicas (Fung, 2004; Wainwright, 2006); e, incluso, particularmente en el contexto latinoamericano, como estrategia de empoderamiento político de los sectores sociales mas desfavorecidos (Abers, 2001; Nylen, 2002).

En este artículo sostenemos que, en realidad, la capacidad transformadora de las prácticas de democracia participativa a nivel local depende del cumplimiento de una

118 serie de condiciones previas, las cuales están relacionadas con lo que la literatura re- 
ciente sobre evaluación de la participación ha identificado como "criterios de calidad participativa" (Parés, 2009; Papadopoulos y Warin, 2007; Font y Blanco, 2006). Concretamente, entendemos que el poder transformador de las prácticas de participación ciudadana depende de: a) La existencia de un liderazgo político fuerte y la asunción transversal de la participación dentro de los aparatos administrativos municipales; b) La amplitud de los márgenes de decisión de la ciudadanía; c) La visibilidad y el conocimiento de los espacios participativos por parte de la población, así como su capacidad de movilización y su representatividad social; d) La evidencia de impactos sobre las decisiones públicas; y e) el cambio en las actitudes políticas de los actores involucrados (concejales, técnicos municipales, asociaciones y los propios participantes).

Tomando como base de estudio las 11 experiencias vigentes de Presupuesto Participativo en la provincia de Barcelona, el artículo que aquí presentamos persigue cinco grandes objetivos. Primero, ofrecer un marco interpretativo sobre las condiciones que fortalecen los impactos de la participación. Segundo, describir las experiencias de Presupuestos Participativos en Barcelona y, de este modo, contribuir a la sistematización del conocimiento sobre este tipo de prácticas participativas en España. Tercero, testar el alcance y los impactos de este tipo de prácticas de participación a partir de los parámetros señalados. Cuarto, observar la incidencia de factores como el tamaño de los municipios o la correlación local de fuerzas políticas en la variabilidad de las experiencias participativas. Y quinto, contribuir a la reflexión sobre las perspectivas políticas de las prácticas locales de participación ciudadana sobre la base de las evidencias empíricas obtenidas.

Empezamos haciendo una justificación teórica de los parámetros de evaluación propuestos. A continuación, explicamos resumidamente el origen y la metodología del estudio del que parte este artículo. Seguidamente, realizamos una descripción de las experiencias de Presupuestos Participativos en Barcelona. A continuación, evaluamos estas experiencias a partir de los criterios que acabamos de mencionar. Y por último, cerramos el artículo con una síntesis de resultados y con unas conclusiones.

\section{CONDICIONES PARA UNA PARTICIPACIÓN TRANSFORMADORA}

Como decíamos en la introducción, la literatura sobre mecanismos de participación ciudadana en las políticas públicas ha tendido hacia una visión optimista sobre los efectos transformadores que ésta puede llegar a generar. La conciencia de los problemas contemporáneos de la democracia liberal-representativa y la preferencia política por una democracia más participativa son la base, más o menos explícita, de tal actitud intelectual.

Tal como indican Barnes et al. (2007) es importante reconocer que los discursos que sustentan la expansión de los mecanismos participativos en las políticas publicas son en realidad diversos, y a menudo contradictorios. Sin embargo, es posible identificar algunas expectativas compartidas. La primera hace referencia a la posibilidad de 
combatir, a través de las prácticas de participación ciudadana, la desafección democrática y la crisis de capital social que subyace en ella. Para Dalton (2004) por ejemplo, este tipo de mecanismos participativos encajan con una ciudadanía cada vez más sofisticada políticamente, con mayores recursos informativos y cognitivos, más especializada en sus intereses temáticos y menos confiada en la capacidad representativa de los partidos políticos o de las instituciones tradicionales. Putnam (2002) incluye este tipo de mecanismos participativos a nivel local dentro de su paquete de medidas "para capitalistas sociales", esperando que puedan contribuir a estimular el interés de la ciudadanía por los asuntos colectivos, reforzar su identificación con la comunidad, y alimentar su sentido de confianza y de reciprocidad con los otros.

Otro de los grandes motivos esgrimidos a favor de la participación ciudadana se refiere a la necesidad de repensar las formas de gobierno ante la creciente complejidad de los problemas públicos (Clarke y Stewart, 1997; Christiensen, 1999). Transformaciones estructurales como la globalización económica, la creciente volatilidad de los mercados laborales, la erosión de los lazos familiares tradicionales, la individualización, o la proliferación de nuevos elementos de identidad y de nuevas formas de acción colectiva se proyectan con fuerza sobre el ámbito local, conllevando mayor fragmentación y mayores incertidumbres. La literatura ha señalado en este sentido como, en contra del credo tecnocrático tradicional, la participación ciudadana no sólo no es un elemento que necesariamente reste eficiencia a los procesos de decisión sino que, al contrario, puede convertirse en un poderoso elemento de mejora de las políticas. Particularmente ante problemas complejos, nos dicen algunos autores, la participación ciudadana puede contribuir al enriquecimiento de la capacidad de diagnóstico de los problemas colectivos, alimentar la creatividad y la innovación política, generar soluciones de equilibrio entre intereses contrapuestos, estimular el sentido de corresponsabilidad de los actores con la implementación de las decisiones y, en último término, gestionar conflictos que de otra forma podrían derivar en un enquistamiento de la toma de decisiones.

Incluso, algunos autores han insistido en el potencial de la participación ciudadana en tanto que estrategia de empoderamiento e inclusión social de los colectivos sociales más desfavorecidos. Se trata de un argumento mucho más extendido en América Latina que en Europa, quizás con la excepción británica, donde se manifiesta una gran preocupación por los efectos particularmente negativos de la erosión del capital social en las comunidades más desfavorecidas (Smith et al., 2007). El argumento, en cambio, toma tintes políticamente más radicales en países latinoamericanos como Brasil, donde organizaciones como el Partido de los Trabajadores defienden la participación popular no sólo como una vía para transformar los procedimientos democráticos, sino sobretodo, como una vía para dar voz a los "sin voz", empoderando políticamente los sectores más desfavorecidos frente a unas instituciones representativas que se consideran contaminadas por la influencia desproporcionada de las elites económicas (Nylen, 2002; Baiocchi, 2003).

Pero, ¿qué condiciones deberían cumplir los mecanismos participativos para lo120 grar tales efectos? En parte, esta pregunta ha sido abordada por la literatura reciente 
sobre evaluación de la "calidad participativa” (Parés, 2009; Papadopoulos y Warin, 2007; Font y Blanco, 2006), aunque se trata de una corriente más preocupada por las características procedimentales que confieren legitimidad democrática a los procesos participativos que por sus efectos o sus consecuencias. Y sin embargo, en diálogo con ella podemos identificar una serie de condiciones que, a nivel teórico, podemos prever que refuercen el alcance transformador de las prácticas de participación.

La primera de ellas se refiere al liderazgo político, que debe ser fuerte y generalizado dentro de la estructura de gobierno municipal. Junto con Haus et al. (2005), entendemos que un liderazgo político fuerte no debería ser contradictorio con los procesos participativos, siempre y cuando no se confunda con el intervencionismo o la voluntad de ejercer un rígido control sobre las dinámicas participativas. Por el contrario, el liderazgo político debe permitir que el proceso participativo ocupe una posición importante dentro de la estructura de gobierno, comprometiendo a aquellos agentes político-administrativos que tienen recursos clave como información, conocimiento experto, competencia política o recursos financieros. En negativo, la ausencia de liderazgo político o de implicación por parte de las áreas de gobierno clave puede condenar a los procesos participativos a ocupar una posición periférica en el proceso cotidiano de elaboración de las políticas.

La segunda condición se refiere a la amplitud de los márgenes de decisión ciudadana. Básicamente, entendemos como tal la capacidad de la ciudadanía de incidir en los múltiples aspectos que en cualquier campo de política pública acostumbran a estar íntimamente interrelacionados. Los márgenes de decisión de la ciudadanía son estrechos cuando sólo se le permite posicionarse sobre aspectos muy concretos de una determinada problemática, excluyéndose del debate otros aspectos que, objetivamente, tienen una incidencia clara sobre la problemática concreta que se está abordando. Por el contrario, los márgenes de decisión ciudadana son amplios cuando la ciudadanía puede discutir la problemática en cuestión desde una perspectiva integral. Así entendida, la literatura demuestra que una de las grandes contribuciones que puede hacer la participación ciudadana a los procesos de elaboración de las políticas públicas es promover miradas holística a los problemas colectivos, superando las rígidas segmentaciones de los problemas que establecen las estructuras burocráticas tradicionales (Wagenaar, 2007).

La tercera condición se refiere a la visibilidad y a la capacidad de movilización de los procesos participativos. Tal como advierten Font y Blanco (2006), cabe distinguir, dentro de esta dimensión, entre varios sub-criterios: el primero y más elemental sería el de la extensión, en el sentido de "cantidad de participantes"; el segundo sería el del pluralismo, en referencia a la diversidad de intereses grupales y organizativos representados en el proceso; el tercero sería el de la representatividad sociodemográfica de los participantes, es decir, la similitud entre el perfil de éstos y la población a la que pertenecen; y el último haría referencia a la visibilidad de la participación entre el conjunto de la población. Los efectos educativos de la participación, por ejemplo, serán inevitablemente muy limitados si los procesos participativos no consiguen ir más allá de las elites participativas habituales y si, al mismo tiempo, la gran mayoría de la pobla- 
ción desconoce su existencia. La contribución de los procesos participativos a la calidad de las políticas puede verse mermada por la ausencia de ciertos colectivos con intereses y con información relevante para el tema que se debate. Por último, difícilmente la participación puede ser socialmente transformadora si sistemáticamente excluye a los colectivos sociales más desfavorecidos, como los inmigrantes.

La cuarta condición se refiere al impacto de las propuestas ciudadanas en las decisiones públicas. Sin pretender que la participación ciudadana implique dejación de responsabilidades políticas por parte de los gobiernos, entendemos que difícilmente ésta puede llegar a tener efectos transformadores significativos si los impactos en las decisiones son nulos o muy débiles. Desde que Arnstein (1969) propusiera su clásica escalera de la participación, en la literatura se han propuesto múltiples tipologías participativas en función del grado de autoridad o poder de los procesos participativos. Fung (2006: 68-60), por ejemplo, ha distinguido recientemente entre cinco grandes modos de participación en función de esta dimensión (aunque, como muchos otros autores, reconoce que ésta no es la única dimensión importante en el momento de establecer tipos participativos):

1) aquellos en los que los ciudadanos sólo pueden aspirar a obtener beneficios personales (información, relaciones sociales, la satisfacción de haber cumplido un deber cívico... );

2) aquellos en los que la participación ejerce una influencia comunicativa sobre las autoridades públicas;

3) los que están específicamente diseñados para el consejo y la consulta;

4) los que generan estructuras de co-gobernanza para el diseño y/o el despliegue de planes y políticas; y

5) los que permiten a la ciudadanía ejercer una autoridad directa sobre las decisiones o los recursos públicos.

Tal como reconoce el mismo autor, ascender en esta escala participativa no implica necesariamente que las decisiones que se deriven de la participación sean mejores o más justas socialmente, pero en todo caso sí que es una condición que favorece el sentido de empoderamiento político entre la ciudadanía y la relevancia de la participación en las políticas.

Por último, el cambio cultural nos parece no sólo una de las posibles consecuencias de los procesos participativos, sino también uno de los requisitos necesarios para que éstos puedan llegar a tener efectos transformadores significativos. Entendemos que este cambio cultural debe producirse en tres niveles: en un nivel político, el reto es transitar desde una cultura del monopolio representativo a una cultura del diálogo y la corresponsabilidad para con la ciudadanía (Subirats, 2003); en un nivel administrativo, el

122 reto consiste en avanzar desde una mentalidad burocrática basada en la lógica del 
"cada uno hace lo que le toca" hacia una mentalidad pos-burocrática basada en el "entre todos debemos hacerlo todo" (Brugué, 2004); y por último, en el nivel ciudadano, el reto es superar la cultura de la pasividad y de la delegación, particularmente extendida en el contexto actual de desafección democrática. Los efectos transformadores de los procesos participativos se ven altamente limitados cuando chocan con ciertas tradiciones culturales contrarias a la participación, sin lograr modificarlas significativamente.

\section{METOdOlogía DEL ESTUdio}

El estudio que aquí presentamos fue el resultado de una iniciativa de la Oficina de Participación Ciudadana (OPC) del Área de Igualdad y Ciudadanía de la Diputación de Barcelona, quien en 2008 decidió impulsar un Grupo de Aprendizaje sobre Presupuestos Participativos. El proceso de constitución y dinamización del Grupo de Aprendizaje no estaba pensado para evaluar sistemáticamente los impactos de los Presupuestos Participativos o sus efectos transformadores, pero sí nos aportó abundante información sobre las principales características de estos procesos, lo cual nos permite calibrar el alcance de estas experiencias en su contexto local e inferir, a partir de los argumentos teóricos presentados, su potencial transformador.

La dinamización de este Grupo de Aprendizaje fue encargada a los autores de este artículo, quienes diseñamos y ejecutamos un proceso de trabajo estructurado en tres grandes etapas:

- Una primera etapa consistente en la elaboración de un informe preliminar sobre las experiencias de Presupuestos Participativos vigentes en la provincia. Este informe se basó en la realización de 30 entrevistas semi-estructuradas en profundidad con un representante político (concejal de participación ciudadana o similar), un técnico/a de participación ciudadana y un representante del tejido asociativo de cada municipio². También se realizó un extenso análisis documental a partir de la información disponible en los sitios Web municipales y de la documentación facilitada por los propios organizadores de cada proceso.

- Una segunda etapa de constitución y desarrollo del Grupo de Aprendizaje. Dicho Grupo lo conformaron representantes técnicos de los Ayuntamientos impulsores de los Presupuestos Participativos ${ }^{3}$, normalmente con el perfil de técnico/a de participación ciudadana. El Grupo celebró 6 sesiones de trabajo de 4 horas de duración. En cada una de ellas se abordó una temática concreta: a) experiencias internacionales de Presupuestos Participativos; b) liderazgos políticos, técnicos y sociales en los procesos de Presupuesto Participativo; c)

2 En todos los casos, se escogió un miembro de una asociación que hubiera participado en la experiencia de los Presupuestos Participativos (y a poder ser en más de una edición), formando parte de la comisión de seguimiento o bien participando en las distintas fases del proceso.

3 Los municipios son: Arenys de Mar, Barberà del Vallès, Callús, Figaró-Montmany, Mataró, Mollet, Parets del Vallès, St. Sadurní d’Anoia, St. Andreu de la Barca, St. Boi de Llobregat, Terrassa. 
metodologías de deliberación y de toma de decisiones; d) comunicación de procesos participativos y movilización ciudadana; y e) criterios de evaluación de la calidad participativa.

- Por último, sobre la base de la corrección y actualización de la información obtenida en la primera fase, y de las discusiones mantenidas a lo largo de las distintas sesiones del Grupo de Aprendizaje, se realizó un informe final que fue presentado en un acto público con los participantes en el Grupo y con representantes de otros Ayuntamientos interesados en impulsar una experiencia de Presupuestos Participativos en sus municipios. Dicho informe final es la base empírica desde la que se escribe este artículo.

\section{PRESUPUESTOS PARTICIPATIVOS EN LA PROVINCIA DE BARCELONA: DESCRIPCIÓN BÁSICA}

Contabilizamos 11 experiencias de Presupuestos Participativos vigentes en la provincia de Barcelona, la mayoría de las cuales fueron impulsadas en el mandato de 2003 a 2007 (Tabla 1$)^{4}$.

\section{TABLA 1}

Presupuestos participativos en la provincia de Barcelona

\begin{tabular}{|l|c|}
\hline \multicolumn{1}{|c|}{ Municipio } & Año inicio \\
\hline Arenys de Mar & 2007 \\
\hline Barberà del Vallès & 2004 \\
\hline Callús & 2002 \\
\hline Figaró-Montmany & 2005 \\
\hline Mataró & 2004 \\
\hline Mollet & 2004 \\
\hline Parets del Vallès & 2005 \\
\hline St. Sadurní d'Anoia & 2006 \\
\hline St. Andreu de la Barca & 2005 \\
\hline St. Boi de Llobregat & 2005 \\
\hline Terrassa & 2005 \\
\hline
\end{tabular}

Fuente: Elaboración propia a partir de las entrevistas

4 Cabe destacar que en Barcelona existieron otras experiencias de Presupuestos Participativos, impulsadas a principios del milenio y que hoy ya no tienen continuidad. Se trata de las experiencias de Rubí y de Sabadell. El hecho que no tuvieran continuidad responde a motivos diferentes en cada caso: en Rubí, IC-V perdió la mayoría en las elecciones municipales de 2003 y el nuevo partido mayoritario, el PSC, decidió no darle continuidad, después de haberse mostrado muy crítico con la experiencia impulsada por el gobierno anterior (Blanco, 2003); en el caso de Sabadell, existió un proceso de participación en los presupuestos municipales en el 2000, pero se trató de un proceso participativo único para toda la legislatura (Subirats et

124 al., 2001). En ambos municipios se han desarrollado nuevos procesos participativos en estos últimos años, aunque ninguno de ellos puede ser calificado como de Presupuesto Participativo. 
Los criterios para la identificación de casos fueron bastante flexibles, en el sentido que aceptamos como Presupuestos Participativos todos aquellos procesos que los propios Ayuntamientos definen como tales, aunque las denominaciones de cada caso son muy variopintas. Es decir, todas las experiencias caben en la definición básica proporcionada por la Red Estatal por los Presupuestos Participativos, para quien “los Presupuestos Participativos son una herramienta de participación y gestión de la ciudad, mediante la cual la ciudadanía puede proponer y decidir sobre el destino de parte de los recursos municipales"', aunque como veremos más abajo, algunas de ellas contienen algunas particularidades metodológicas que permitirían dudar sobre si cabe calificarlas o no como Presupuestos Participativos, como por ejemplo el hecho de que no se discuta explícitamente el costo de los proyectos propuestos ni su encaje en el presupuesto (Pires y Pineda, 2008).

A continuación, ofrecemos algunos detalles más sobre las características de los procesos analizados. Empezamos con una breve caracterización de los municipios donde se llevan a cabo los Presupuestos Participativos, para luego ahondar en la explicación de sus rasgos organizativos fundamentales.

\section{Tipo de municipios}

Los 11 municipios de la provincia de Barcelona con una experiencia vigente de Presupuesto Participativo son muy diversos desde el punto de vista de su tamaño (Tabla 2). En un extremo, municipios como El Figaró y Callús se sitúan alrededor de los 1.000 habitantes, mientras que en el otro, encontramos grandes municipios de la primera corona metropolitana de Barcelona como Terrassa (202.136 habitantes), Mataró (119.035 habitantes) y Sant Boi de Llobregat (80.727 habitantes). Cabe destacar, sin embargo, el peso significativo de los municipios pequeños, sobre todo si tenemos en cuenta que, a principios del milenio, los municipios más innovadores en términos de participación ciudadana en la provincia de Barcelona (y en el conjunto de Cataluña) fueron municipios grandes cercanos a Barcelona (como Rubí, Sant Feliu de Llobregat o El Prat de Llobregat) (Subirats et al., 2001). La muestra de experiencias de Presupuestos Participativos con la que trabajamos, por lo tanto, ilustra una tendencia de expansión y diversificación territorial de las prácticas locales de innovación democrática en la provincia.

Si bien desde el punto de vista territorial se trata de municipios muy diversos, no podemos decir lo mismo, en cambio, con respecto a su orientación política (Tabla 2). La gran mayoría de municipios están gobernados por el Partit dels Socialistes de Catalunya (PSC), aunque, también en la mayoría de los casos, este partido gobierna en coalición con otras formaciones políticas, siendo la composición de estas coaliciones variable según los casos. Tal predominio de gobiernos socialistas en la mues-

5 Ver en: <http//:www.presupuestosparticipativos.com>. Como se verá en la explicación de la metodología, no todas las experiencias cumplen con los criterios utilizados por esta Red 


\section{GRÁFICO}

Tamaño de los municipios con Presupuestos Participativos (2007)

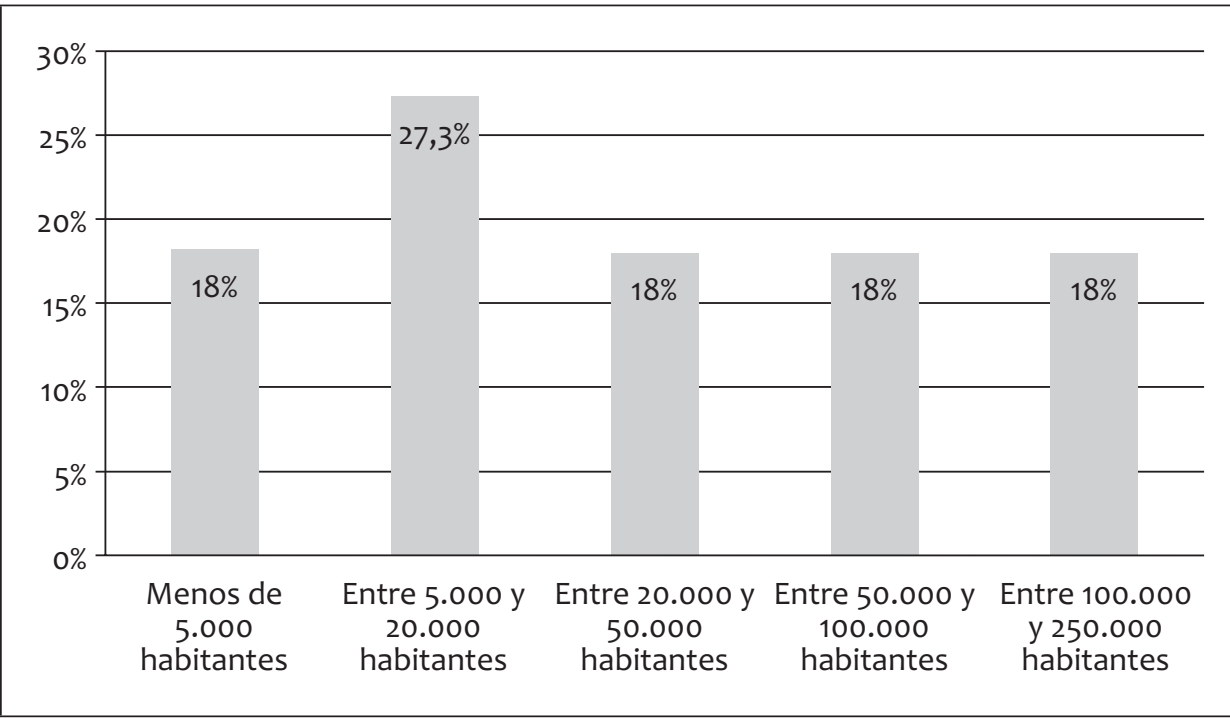

Fuente: Elaboración propia a partir de datos de Idescat.

TABLA 2

Composición del gobierno en el mandato en que se impulsan los presupuestos participativos

126 Fuente: Elaboración propia.

\begin{tabular}{|c|c|}
\hline Municipio & $\begin{array}{c}\text { Coalición de gobierno } \\
\text { (En negrita el partido principal) }\end{array}$ \\
\hline Arenys de Mar & $P S C-E R C-I C V$ \\
\hline Barberà del Vallès & $P S C-I C V-E R C$ \\
\hline Callús & $M A C-P S C$ \\
\hline Figaró & $C A F$ \\
\hline Mataró & $P S C-I C V-E R C$ \\
\hline Mollet & $P S C-I C V$ \\
\hline Parets del Vallès & $P S C-I C V$ \\
\hline St. Sadurní d'Anoia & $C I U-E R C-A M I$ \\
\hline St. Andreu de la Barca & PSC \\
\hline St. Boi de Llobregat & $P S C-I C V$ \\
\hline Terrassa & $P S C-I C V-E R C$ \\
\hline
\end{tabular}


tra responde, a nuestro entender, a dos fenómenos distintos: el primero, el propio predominio electoral del PSC en la provincia de Barcelona; el segundo, la influencia en este partido de la organización Ciutadans pel Canvi, quien ha protagonizado en estos últimos años la campaña pro-Presupuestos Participativos "Els calers on calen" ("El dinero donde es necesario") 6 . Iniciativa per Catalunya - Verds (IC-V), quien a principios del milenio lideró buena parte de las experiencias de innovación democrática en los municipios catalanes (Subirats et al., 2001), continúa teniendo una presencia significativa en las coaliciones de gobierno de los municipios barceloneses con presupuestos participativos. Cabe destacar, también, el peso de las candidaturas políticas independientes, particularmente en los municipios más pequeños (Callús, El Figaró y Sant Sadurní).

Las entrevistas realizadas nos permiten caracterizar someramente la composición y dinámica del tejido asociativo de estos municipios. Si bien el hecho de disponer sólo de impresiones al respecto no nos permite ahondar en el análisis comparado, sí podemos identificar una tendencia compartida en todos ellos: la mayoría de personas entrevistadas coincide en describir un panorama asociativo marcado por la fragmentación, la debilidad de las asociaciones vecinales, y el predomino de entidades especializadas (mayoritariamente culturales y deportivas y, en general, con escasas pretensiones políticas). Este dato nos parece relevante para contextualizar la aparente poca relevancia de las asociaciones en tanto que actor en muchas de las experiencias participativas estudiadas, aspecto que analizaremos posteriormente.

Por último, las mismas entrevistas y el análisis documental nos permiten constatar que en ninguno de estos municipios los Presupuestos Participativos son una experiencia de participación ciudadana aislada. Todos ellos disponen de una red más o menos compleja de dispositivos participativos al margen de los Presupuestos Participativos, aunque podemos establecer una clara diferenciación entre municipios que apuestan, fundamentalmente, por mecanismos participativos con un formato convencional, básicamente, consejos consultivos de base asociativa (Arenys de Mar, Mataró, Mollet, Sant Andreu de la Barca) y otros que, en cambio, han hecho una apuesta clara por complementar este tipo de mecanismos con otros procesos participativos más innovadores (Barberà del Vallès, Figaró-Montmany, Callús, Parets del Vallès, Sant Sadurní d’Anoia, Sant Boi, Terrassa).

\section{Modelos de Presupuesto Participativo}

Al profundizar en los rasgos organizativos de los Presupuestos Participativos de la provincia de Barcelona, observamos la existencia de una gran diversidad de experiencias, lo cual confirma el hecho que los Presupuestos Participativos no representan una metodología participativa específica, sino una temática para la participación (Sintomer, 2005). 
Si las primeras experiencias de Presupuestos Participativos en España, como las de Rubí o Córdoba, seguían claramente el modelo brasileño (basado en asambleas territoriales y temáticas, criterios preestablecidos de priorización de propuestas, caravanas de prioridades, y consejos del Presupuesto Participativo) (Ganuza y Alvarez, 2003), las experiencias vigentes en Barcelona, en cambio, tienden a apartarse de este modelo, adaptando las metodologías al contexto local.

Los Presupuestos Participativos acostumbran a ser procesos organizativamente muy complejos que, además, evolucionan de manera significativa con el tiempo, con lo cual no existe espacio aquí para ahondar en los detalles metodológicos de cada uno de los casos estudiados. Sin embargo, a partir de un análisis global de las distintas experiencias, podemos identificar aspectos comunes y aspectos que definen modelos diferenciados.

En cuanto a los aspectos comunes, cabe destacar, sobre todo, la organización de los procesos participativos en distintas fases que por lo general se repiten anualmente, de acuerdo con el ciclo presupuestario7. Así, en una primera fase se despliegan distintas herramientas encaminadas a difundir la experiencia entre el conjunto de la población. En una segunda fase, se abren distintos espacios para que la ciudadanía formule sus propuestas. En una tercera fase, el Ayuntamiento analiza esas propuestas a partir de criterios como la competencia jurídica, la viabilidad técnica o, incluso, en algunos casos, el coste estimado de cada propuesta. En una cuarta fase, se votan o se priorizan las propuestas que han pasado el filtro anterior. Tras incorporarse en el presupuesto y aprobarse en el Pleno Municipal, algunos municipios constituyen un órgano de seguimiento que controla la ejecución de las propuestas aprobadas.

En cuanto a los criterios de diferenciación, en cambio, cabe destacar la existencia de tres grandes modelos organizativos basados en lógicas participativas muy distintas ${ }^{8}$ :

- El primer modelo se fundamenta en una lógica de participación extensiva: el proceso está abierto en todas sus etapas a la participación de cualquier ciudadano que quiera participar, combina una gran cantidad de herramientas al respecto (urnas en equipamientos públicos, espacios virtuales...), y otorga una gran importancia a la votación final de las propuestas a través de consultas populares o referéndum. El caso de Callús sería paradigmático en este sentido (Cuadro 1).

- El segundo modelo, en cambio, se fundamenta en una lógica de participación representativa: la participación se restringe en la mayoría de las etapas a órga-

7 Cabe destacar algunas excepciones: En el caso de Terrassa, el año 2008 se pasa a realizar el proceso cada cuatro años sobre el presupuesto de inversiones. En el caso de Sant Boi de Llobregat, después de dos ediciones, en el año 2008 se deja de repetir la experiencia. Finalmente, en el caso de Sant Sadurní d'Anoia se ha parado temporalmente la reedición del proceso cuando éste ha coincidido con los años electorales.

8 Básicamente, estos son los mismos modelos detectados por Ganuza (2005) en su estudio comparado de experiencias en España. 
nos sectoriales o territoriales, en muchos casos preexistentes, como los Consejos Territoriales o los Consejos Sectoriales. La participación en estos consejos es mayoritariamente asociativa, con lo que las posibilidades de participación de la ciudadanía a título individual son bastante restrictivas (aunque no necesariamente inexistentes). Sant Boi de Llobregat, Mataró y Mollet tienden hacia este modelo (Cuadro 2).

- Por último, otros municipios como Parets del Vallès y El Figaró optan por una lógica de participación mixta, combinándose espacios de participación extensiva (asambleas abiertas, consultas populares... ) con otros espacios de participación representativa (consejos, comisiones, grupos de trabajo... ) (Figura 3).

\section{CUADRO 1}

Lógica de participación extensiva: el caso de Callús

\begin{tabular}{|l|l|}
\hline \multicolumn{1}{|c|}{ Etapas del proceso } & \multicolumn{1}{|c|}{ Canales y criterios de participación } \\
\hline 1. Presentación de propuestas & $\begin{array}{l}\text { Todo el mundo puede presentar propuestas, } \\
\text { presencialmente vía urnas o mediante la web } \\
\text { municipal. }\end{array}$ \\
\hline 2. Difusión y discusión de las propuestas & $\begin{array}{l}\text { Mediante la web municipal, panfletos y re- } \\
\text { uniones. Cualquier persona puede hacer co- } \\
\text { mentarios o sugerencias en relación a las } \\
\text { propuestas. }\end{array}$ \\
\hline 3. Votación & $\begin{array}{l}\text { Virtualmente a través de la web, o mediante } \\
\text { urnas ubicadas en equipamientos municipa- } \\
\text { les y establecimientos. Pueden votar los ma- } \\
\text { yores de 14 años empadronados. }\end{array}$ \\
\hline
\end{tabular}

Fuente: Elaboración propia.

\section{CUADRO 2}

Lógica de participación representativa: el caso de Sant Boi de Llobregat

\begin{tabular}{|l|l|}
\hline \multicolumn{1}{|c|}{ Etapas del proceso } & \multicolumn{1}{|c|}{ Canales y criterios de participación } \\
\hline 1. Presentación de propuestas & $\begin{array}{l}\text { Por parte de la ciudadanía: mediante urnas, } \\
\text { web, oficinas ciudadanas. Por parte de las } \\
\text { asociaciones, en el marco de los Consejos de } \\
\text { barrio. }\end{array}$ \\
\hline 2. Valoración técnica/económica & $\begin{array}{l}\text { A cargo de los técnicos municipales, y pre- } \\
\text { sentación de los resultados en los Consejos } \\
\text { de barrio. }\end{array}$ \\
\hline 3. Priorización & En el marco de los Consejos de barrio. \\
\hline 4. Validación final & $\begin{array}{l}\text { Presentación de la propuestas priorizadas y } \\
\text { validación por parte del Consejo de ciudad. }\end{array}$ \\
\hline
\end{tabular}

Fuente: Elaboración propia. 


\section{CUADRO 3}

Lógica de participación mixta: el caso de el Figaró-Montmany

\begin{tabular}{|l|l|}
\hline \multicolumn{1}{|c|}{ Etapas del proceso } & \multicolumn{1}{|c|}{ Canales y criterios de participación } \\
\hline 1. Presentación de propuestas & $\begin{array}{l}\text { Todo el mundo puede presentar propuestas, } \\
\text { presencialmente mediante urnas, vía web, al } \\
\text { Consejo de Pueblo, en comercios y vía Cua- } \\
\text { derno Familiar. }\end{array}$ \\
\hline 2. Valoración de las propuestas & $\begin{array}{l}\text { En el marco de la Comisión Permanente de } \\
\text { Participación, aplicando criterios prefijados. }\end{array}$ \\
\hline 3. Priorización & $\begin{array}{l}\text { A partir de criterios de necesidad básica } \\
(10 \%) \text { y perspectiva estratégica (15\%) valo- } \\
\text { rados por la Comisión Permanente, y por vo- } \\
\text { tación popular (75\%) de mayores de 16 años } \\
\text { empadronados. }\end{array}$ \\
\hline 4. Presentación de resultados & En Audiencia Pública. \\
\hline
\end{tabular}

Fuente: Elaboración propia.

A priori, estos modelos gestionan de forma distinta el clásico trade-off entre inclusividad y calidad deliberativa (Fishkin, 1995). Los que siguen el primer modelo permiten romper con el monopolio representativo de las asociaciones, aunque lo hacen a expensas de la calidad del debate entre los participantes. Por el contrario, los que siguen el segundo modelo, consiguen establecer debates sobre la base de la experiencia acumulada de los representantes de las asociaciones, aunque lo hacen a expensas de la inclusividad del proceso con respecto a la ciudadanía no asociada. El tercer modelo, por lo tanto, permite aprovechar los aspectos más positivos de cada una de las lógicas participativas anteriores, aunque lo hace a costa de una mayor complejidad organizativa.

\section{EL ALCANCE Y LOS IMPACTOS DE LOS PRESUPUESTOS PARTICIPATIVOS}

Analizaremos a continuación los rendimientos de las experiencias analizadas de Presupuestos Participativos a partir de los parámetros señalados en la introducción. Hablaremos, en primer lugar, del liderazgo político y del encaje institucional de los Presupuestos Participativos en la estructura político-administrativa municipal. En segundo lugar, haremos referencia a la amplitud de los márgenes de decisión ciudadana dentro de los Presupuestos Participativos. En tercer lugar, analizaremos el grado de participación y de representatividad social de los participantes. En cuarto lugar, valoraremos los impactos de la participación sobre la toma de decisiones presupuestarias. Y por último, observaremos los efectos del proceso participativo sobre las ac-

130 titudes políticas de los actores locales. 


\section{Liderazgo político y encaje institucional}

El liderazgo político de todos los casos estudiados recae sobre las concejalías de participación ciudadana (las cuales adquieren nomenclaturas distintas según los casos). En algunos municipios, como en El Figaró o Arenys de Mar, se menciona que la iniciativa del impulso de los Presupuestos Participativos recayó en la alcaldía y que ésta ha continuado apoyando activamente el proceso a pesar de haber delegado sobre la concejalía de participación su gestión operativa. Tal aspecto se valora positivamente, en la medida que contribuye a moderar el aislamiento institucional de la concejalía de participación. También se subraya como una experiencia positiva la creación de órganos ad hoc compuestos por representantes políticos y/o técnicos de las distintas áreas del Ayuntamiento para hacer el seguimiento del Presupuesto Participativo, como sucede por ejemplo con las Comisiones de Seguimiento Político y Técnico del Ayuntamiento de Terrassa?.

Sin embargo, en la gran mayoría de los casos, los técnicos de participación ciudadana consideran que el Presupuesto Participativo todavía no ha sido asumido transversalmente por el Ayuntamiento y, más bien, lamentan la escasa implicación de algunas concejalías clave. A continuación, exponemos algunas citas literales de nuestras entrevistas que ilustran esta percepción:

Técnica de participación: [las otras áreas] “... todavía son receptoras de estos procesos y los ven como algo a parte de sus departamentos".

Técnica de participación: "Aunque este año ha mejorado el nivel de implicación de los técnicos, no conseguimos que fueran ellos los que hiciesen la devolución a la ciudadanía en las asambleas. Tengo que hacerlo yo y no es los mismo ya que debo leer lo que me pasan...".

Técnico de participación: "Nos encontramos con dificultades asociadas a resistencias funcionariales... Incluso tuve que hacer yo mismo el informe técnico, jurídico y de viabilidad de las propuestas".

Tal situación es particularmente problemática cuando se analiza la implicación de las áreas de Urbanismo, claves en los Presupuestos Participativos, dada su afectación sobre proyectos de inversión urbana. Así, según el relato de los propios técnicos de participación ciudadana y de los representantes del tejido asociativo, los técnicos y responsables políticos del área de urbanismo tienden a percibir el Presupuesto Participativo como un hecho ajeno a su propia área y como algo que

9 La Comisión Política está formada por representantes de todos los grupos municipales y su función principal es la de seguimiento del proceso. La Comisión Técnica la integran profesionales de las distintas áreas municipales vinculadas al proceso. Es la responsable de validar y cuantificar económicamente las propuestas ciudadanas y crear materiales informativos de soporte. 
sólo les sobrecarga de trabajo, sin redundar en una mejora de sus tareas cotidianas. Según el mismo relato, en la mayoría de estas áreas continúan predominando las actitudes de escepticismo, cuando no de rechazo, hacia la implicación directa de la ciudadanía en el diseño de las políticas públicas, fruto de una cultura corporativa que se considera como mayoritariamente tecnocrática. Así lo expresaron algunas de las personas que entrevistamos:

Representante tejido asociativo: "Parece que no se terminan de creer esto de la participación ciudadana ya que no se detecta un gran esfuerzo por parte de las otras áreas. La percepción que tiene el ciudadano es que Urbanismo es el más cerrado a la participación externa".

Técnica de participación: "Hay técnicos como los de Urbanismo que delante de determinadas propuestas ciudadanas dicen: ‘Pero esto qué es? ¡Yo que tenía mi plan...!'”

Sólo en la experiencia de El Figaró se puede observar con claridad un liderazgo político fuerte, por parte de una alcaldesa que a su vez es la responsable política de participación ciudadana, junto con una asunción claramente transversal del proceso dentro del Ayuntamiento. Seguramente, más allá de las convicciones políticas del equipo de gobierno municipal, la coordinación de las distintas áreas se ve facilitada por el escaso tamaño de este Ayuntamiento.

\section{Amplitud de los márgenes de decisión ciudadana}

La amplitud de los márgenes de decisión ciudadana en el marco de los Presupuestos Participativos puede observarse a través de los ámbitos del presupuesto municipal que se someten a la consideración de la ciudadanía. Los casos de Barcelona se asemejan a la mayoría de experiencias conocidas a nivel internacional (Sintomer, 2005; Sintomer et al., 2008) en el sentido que la participación se centra en el gasto y no en los ingresos municipales y también en el sentido que, mayoritariamente, la participación concierne a las inversiones municipales, excluyéndose otros capítulos (Tabla 3$)^{10}$.

10 Como es sabido, los capítulos del gasto en un presupuesto municipal son nueve: el capítulo 1, de gastos del personal; el capítulo 2, de gasto de bienes corrientes y de servicios; el capítulo 3, de gastos financieros; el capítulo 4, de transferencias corrientes; el capítulo 5, que queda abierto; el capítulo 6, de inversiones reales; el capítulo 7, de transferencias de capital; el capítulo 8, de activos financieros; y el capítulo 9, de pasivos. Dentro del presupuesto, hay una serie de conceptos que podrían considerarse "fijos", como los de gasto de personal, la mayor parte de gastos corrientes, gastos comprometidos en contratos a largo plazo con terceros, u otros gastos derivados de operaciones financieras. Sin embargo, resulta muy difíci determinar un porcentaje exacto de los gastos “fijos" sobre el total, ya que lo que es considerado fijo varía mucho en función de los municipios y, además, la determinación de lo que es fijo o no siempre es opinable. Por ello hemos optado por hablar del porcentaje con respecto al total del presupuesto o con respecto al total de inversiones, aunque este dato pueda resultar dudoso dada la magnitud de los gastos que puedan 
TABLA 3

Partidas presupuestarias e influencia en las decisiones en los municipios con Presupuestos Participativos

\begin{tabular}{|c|c|c|c|}
\hline $\begin{array}{l}\text { Municipio } \\
\text { (núm. de } \\
\text { habitantes) }\end{array}$ & $\begin{array}{l}\text { Partida sometida } \\
\text { a participación } \\
\text { (\% sobre el total del } \\
\text { Presupuesto) } \\
\end{array}$ & Límites temáticos & Dimensión \\
\hline $\begin{array}{l}\text { Arenys de Mar } \\
\quad(14.164)\end{array}$ & $\begin{array}{c}175.000 € \\
0,94 \%\end{array}$ & $\begin{array}{c}\text { Proyectos de } \\
\text { mantenimiento y mejora } \\
\text { del espacio público }\end{array}$ & $\begin{array}{l}\text { Capítulo de } \\
\text { inversiones }\end{array}$ \\
\hline $\begin{array}{l}\text { Barberà del Vallès } \\
\quad(29.208)\end{array}$ & $\begin{array}{c}\text { No hay partida } \\
\text { específica } \\
\text { \% variable según la } \\
\text { edición }\end{array}$ & \multicolumn{2}{|c|}{ Temática anual del Plan de Ciudad } \\
\hline Callús (1.610) & $\begin{array}{c}24.000 € \\
0,89 \%\end{array}$ & Cualquier temática & $\begin{array}{l}\text { Capítulo de } \\
\text { transferencias } \\
\text { corrientes }\end{array}$ \\
\hline $\begin{array}{c}\text { Figaró-Montmany } \\
(1.009)\end{array}$ & $\begin{array}{c}150.000 € \\
7,92 \%\end{array}$ & $\begin{array}{l}\text { Se excluyen gastos } \\
\text { plurianuales }\end{array}$ & $\begin{array}{c}\text { Cualquier concepto } \\
\text { del gasto }\end{array}$ \\
\hline Mataró (119.035) & $\begin{array}{c}\text { No hay partida } \\
\text { específica. Globalidad } \\
\text { del PAM y Presupuesto }\end{array}$ & Cualquier temática & Cualquier temática \\
\hline Mollet (51.365) & $\begin{array}{l}\text { No hay partida } \\
\text { específica } \\
\text { \% variable según la } \\
\text { edición }\end{array}$ & Cualquier temática & Cualquier temática \\
\hline $\begin{array}{l}\text { Parets del Vallès } \\
\quad(16.720)\end{array}$ & $\begin{array}{c}300.000 € \\
1,35 \%\end{array}$ & $\begin{array}{l}\text { Proyectos de mejora de } \\
\text { equipamientos y espacio } \\
\text { público }\end{array}$ & $\begin{array}{l}\text { Capítulo de } \\
\text { inversiones }\end{array}$ \\
\hline $\begin{array}{c}\text { St. Sadurní } \\
\text { d'Anoia (11.790) }\end{array}$ & $\begin{array}{l}450.000 € \\
\text { (s.d.) }\end{array}$ & $\begin{array}{l}\text { Proyectos de mejora del } \\
\text { espacio público (medio } \\
\text { urbano, alumbrados, } \\
\text { parques y jardines) }\end{array}$ & $\begin{array}{l}\text { Capítulo de } \\
\text { inversiones }\end{array}$ \\
\hline $\begin{array}{l}\text { St. Andreu de la } \\
\text { Barca }(25.743)\end{array}$ & $\begin{array}{c}35.000 € \\
0,2 \%\end{array}$ & Cualquier temática & $\begin{array}{l}\text { Capítulo de } \\
\text { inversiones }\end{array}$ \\
\hline $\begin{array}{c}\text { St. Boi de } \\
\text { Llobregat }(80.727)\end{array}$ & $\begin{array}{c}1.500 .000 € \\
1,46 \%\end{array}$ & $\begin{array}{c}\text { Proyectos de } \\
\text { mantenimiento y mejora } \\
\text { del espacio público (por } \\
\text { barrios) }\end{array}$ & $\begin{array}{l}\text { Capítulo de } \\
\text { inversiones }\end{array}$ \\
\hline Terrassa (202.136) & $\begin{array}{c}1.000 .000 € \\
0,63 \%\end{array}$ & $\begin{array}{l}\text { A nivel de ciudad, } \\
\text { cualquier temática. } \\
\text { A nivel de barrio, } \\
\text { proyectos de } \\
\text { mantenimiento del } \\
\text { espacio público }\end{array}$ & $\begin{array}{l}\text { Capítulo de } \\
\text { inversiones }\end{array}$ \\
\hline
\end{tabular}

Fuente: Elaboración propia. 
Cabe destacar la singularidad de los casos de Mollet, Mataró y Barberà del Vallès, porque en ninguno de ellos la ciudadanía discute explícitamente sobre las finanzas municipales. En el caso de Mollet, las propuestas ciudadanas se incorporan al Programa de Actuación Municipal (PAM) sin una asignación presupuestaria específica. En el caso de Mataró, se incorporan simultáneamente al PAM y al presupuesto municipal, aunque con dos límites importantes: la ciudadanía prioriza las propuestas que el propio Ayuntamiento formula en el marco de un Documento de Prioridades; y la incorporación de las propuestas al presupuesto municipal la realiza el propio equipo de gobierno municipal, sin que en ningún momento del proceso la ciudadanía haya discutido explícitamente sobre cómo ajustar las prioridades establecidas con los recursos financieros disponibles. Por último, en Barberà del Vallès, el Ayuntamiento plantea cada año una o varias temáticas concretas de acuerdo con las prioridades establecidas en el Plan de Ciudad (también elaborado participativamente), de manera que la ciudadanía participa en el diseño de proyectos de actuación en relación a esas temáticas, correspondiendo la valoración económica de esos proyectos y su encaje en el presupuesto municipal al propio equipo de gobierno.

En el resto de casos, los límites a la participación ciudadana se establecen por dos vías. La primera, común a todas estas experiencias, es la fijación de una determinada cantidad de dinero (o porcentaje del presupuesto de inversiones) como tope sobre el cual la ciudadanía puede decidir. Esta cantidad varía significativamente en función de los casos y su comparación resulta muy complicada dada la gran diferencia de tamaño entre municipios, aunque podemos afirmar que en la mayoría de los casos representa entre el 0,5 y el $2 \%$ del total del presupuesto municipal o, expresado de otro modo, entre el 5 y el 10\% del capítulo de inversiones ${ }^{11}$. Es el caso de Arenys de Mar, Parets del Vallès, Sant Sadurní d'Anoia, Sant Andreu de la Barca, Sant Boi o Terrassa. En Callús, se somete a participación la cantidad disponible en el capítulo de transferencias corrientes (subvenciones recibidas por el Ayuntamiento para financiar operaciones corrientes). En El Figaró-Montmany, en cambio, se puede proponer cualquier proyecto independientemente del capítulo del gasto a que haga referencia, siendo el principal límite que no implique gastos plurianuales.

La otra vía de limitación de la participación, que no es excluyente con la anterior, es el establecimiento de límites temáticos explícitos. En varios casos, se circunscribe el ámbito de discusión a proyectos de construcción, mantenimiento o mejora de equipamientos, infraestructuras y vía publica (Arenys de Mar, Parets del Valles, Sant Sadurní d’Anoia, Terrassa y Sant Boi de Llobregat). En el caso de Sant Boi de

11 En realidad, el porcentaje sobre el total de inversiones es muy variable según los casos. Si bien la mayoría se sitúan entre el 5 y el 10\%, hay otros casos extremos como St. Andreu de la Barca, donde la cifra baja alrededor del 1\%, o el de St. Sadurní d’Anoia, donde ésta se eleva hasta cerca del 20\%. Sin embargo,

134 estas fuertes variaciones se explican, en parte, por la desigual capacidad inversora de unos municipios u otros, lo que dificulta la comparabilidad de los datos. 
Llobregat, además, se establece que las propuestas de inversión deben tener una escala de barrio.

A todo ello cabe añadir un elemento más, reconocido por los técnicos de participación en las discusiones mantenidas en el Grupo de Aprendizaje: el elevado poder de filtro de las propuestas ciudadanas por parte del Ayuntamiento. Así, en la mayoría de experiencias, los técnicos municipales deben analizar las propuestas ciudadanas antes de ser sometidas a votación final, de acuerdo con criterios de competencia jurídica, viabilidad técnica y viabilidad económica. A pesar de la aparente neutralidad de tales criterios, ciertos segmentos de la ciudadanía han criticado que las propuestas descartadas son excesivas y que los criterios para hacerlo pueden esconder motivaciones políticas, y no sólo técnicas.

Por último, cabe destacar de nuevo la singularidad del caso de El Fígaro, el único municipio de los estudiados que, siguiendo el ejemplo brasileño, pondera las propuestas no sólo a partir de las votaciones, sino también a partir de otros criterios referentes a los efectos redistributivos y la perspectiva estratégica de los proyectos.

\section{Participación y representatividad social}

Las cifras de participación son muy desiguales en función de las experiencias, lo cual se explica por dos grandes motivos. El primero y más evidente tiene que ver con las grandes diferencias de tamaño entre municipios. El segundo, con la gran diversidad de metodologías utilizadas.

Sin embargo, desde el punto de vista de la extensión participativa, podemos detectar dos tendencias bastante claras (Tabla 4). La primera, que los volúmenes de participación son, en términos generales, bastante bajos. La segunda, ya observada por otros estudios en España (Ganuza y Gómez, 2008), es que, en términos relativos, éstos tienden a ser bastante más altos en los municipios pequeños (como Callús, El Figaró o Arenys de Mar) que en los municipios grandes (como Mataró, Terrassa o Sant Boi de Llobregat).

Los modelos participativos adoptados, en cambio, no tienen un efecto claro sobre la cantidad de participantes. Si bien en un principio podríamos prever que la lógica de participación extensiva debería promover una participación más cuantiosa, observamos que, en realidad, los municipios que apuestan por una participación asociativa pueden demostrar volúmenes de participación similares a los primeros.

Más importante que la extensión de la participación, sin embargo, puede ser el grado de pluralismo asociativo o el grado de representatividad social de los participantes (Font y Blanco, 2006). Sin embargo, los Ayuntamientos no disponen de informaciones precisas en ninguno de estos sentidos. Así, para la mayoría de los casos, sólo podemos basarnos en las impresiones de las personas consultadas. 
TABLA 4

Participación en los presupuestos participativos

\begin{tabular}{|c|c|c|c|c|}
\hline \multirow[b]{2}{*}{$\begin{array}{c}\text { Municipio } \\
\text { (n. }{ }^{\circ} \text { de } \\
\text { habitantes) }\end{array}$} & \multicolumn{2}{|c|}{ Fase de propuestas } & \multicolumn{2}{|c|}{ Fase de votaciones } \\
\hline & $\begin{array}{l}\text { Lógica de } \\
\text { participación }\end{array}$ & $\begin{array}{l}\text { Participantes } \\
\text { (n. }{ }^{\circ} \text { personas) }\end{array}$ & $\begin{array}{l}\text { Lógica de } \\
\text { participación }\end{array}$ & $\begin{array}{l}\text { Participantes } \\
\text { (n. personas) }\end{array}$ \\
\hline $\begin{array}{c}\text { Arenys de Mar } \\
\quad(14.164)\end{array}$ & Extensiva & 11 & $\begin{array}{c}\text { Extensiva } \\
\text { (mayores de } 16 \\
\text { años } \\
\text { empadronados) } \\
\end{array}$ & 353 \\
\hline $\begin{array}{c}\text { Barberà del } \\
\text { Vallès }(29.208) \\
\end{array}$ & Extensiva & 246 & \multicolumn{2}{|c|}{ No hay distinción entre fases } \\
\hline Callús (1.610) & Extensiva & 17 & $\begin{array}{c}\text { Extensiva } \\
\text { (mayores } \\
\text { de } 14 \text { años } \\
\text { empadronados) }\end{array}$ & 163 \\
\hline $\begin{array}{l}\text { Figaró- } \\
\text { Montmany } \\
(1.009) \\
\end{array}$ & Extensiva & - & $\begin{array}{c}\text { Mixta (mayores } \\
\text { de } 16 \text { años } \\
\text { empadronados) }\end{array}$ & 262 \\
\hline Mataró (119.035) & Representativa & 400 & \multicolumn{2}{|c|}{ Equipo de gobierno } \\
\hline Mollet (51.365) & $\begin{array}{c}\text { Mixta (ciudadanos } \\
\text { mayores de } 16 \text { años } \\
\text { empadronados) }\end{array}$ & $\begin{array}{c}245 \text { y } 5 \\
\text { asociaciones }\end{array}$ & Representativa & s.d. \\
\hline $\begin{array}{c}\text { Parets del Vallès } \\
(16.720)\end{array}$ & $\begin{array}{c}\text { Extensiva (mayores } \\
\text { de } 12 \text { años } \\
\text { vinculados al } \\
\text { municipio) } \\
\end{array}$ & 217 & $\begin{array}{c}\text { Extensiva } \\
\text { (mayores de } 12 \\
\text { años vinculados al } \\
\text { municipio) }\end{array}$ & 1.149 \\
\hline $\begin{array}{c}\text { St. Sadurní } \\
\text { d'Anoia (11.790) }\end{array}$ & $\begin{array}{c}\text { Extensiva (pero se } \\
\text { crea un grupo de } 25 \\
\text { personas escogidas } \\
\text { por los grupos } \\
\text { municipales) }\end{array}$ & 25 & $\begin{array}{l}\text { Asistencia al } \\
\text { primer taller }\end{array}$ & 11 \\
\hline $\begin{array}{l}\text { St. Andreu de la } \\
\text { Barca }(25.743)\end{array}$ & Extensiva & 15 & Extensiva & 25 \\
\hline $\begin{array}{c}\text { St. Boi de } \\
\text { Llobregat } \\
(80.727)\end{array}$ & Mixta & $\begin{array}{c}75 \text { y } 23 \\
\text { asociaciones }\end{array}$ & Representativa & $\begin{array}{c}57 \\
\text { asociaciones }\end{array}$ \\
\hline $\begin{array}{l}\text { Terrassa } \\
(202.136)\end{array}$ & $\begin{array}{c}\text { Extensiva } \\
\text { (Para formar parte } \\
\text { del Consejo } \\
\text { Plenario: mayores } \\
\text { de } 16 \text { años, } \\
\text { vinculados al } \\
\text { municipio. } \\
\text { Para formular } \\
\text { propuestas: } \\
\text { asistencia mínima a } \\
2 \text { talleres) } \\
\end{array}$ & 198 & $\begin{array}{c}\text { Extensiva } \\
\text { (Formar parte del } \\
\text { Consejo plenario) }\end{array}$ & 135 \\
\hline
\end{tabular}

136 Fuente: Elaboración propia. 
Respecto a la participación asociativa, podemos inferir de las entrevistas y discusiones en el Grupo de Aprendizaje que ésta ha tendido a ser más intensa y plural en los casos en que la participación se ha canalizado a través de órganos estables de participación como los Consejos sectoriales o el Consejo de ciudad (Mataró y Sant Boi de Llobregat). En cambio, en aquellos municipios donde se ha apostado predominantemente por una lógica extensiva, las asociaciones han jugado un papel poco relevante, si bien no han ejercido una estrategia de oposición a los Presupuestos Participativos como sucedió con algunas entidades (particularmente las vecinales) en ciudades como Córdoba (Ganuza, 2003) o Rubí (Blanco, 2003). Algunas de las personas entrevistadas destacan, en este sentido, que el distanciamiento asociativo con respecto a los presupuestos participativos responde, fundamentalmente, a la falta de incentivos para la participación:

Técnica de participación: “Las asociaciones tienen más vía directa con la administración y ya tienen sus canales ordinarios para hacer propuestas; en cambio, era a la ciudadanía a quien le faltaba esta vía".

Representante tejido asociativo: "Cuando empezó la experiencia todo el mundo pensaba que su asociación saldría beneficiada. Pero cuando se dan cuenta de que se debe mirar por el conjunto del pueblo, entonces se descuelgan más... El hecho de que algunas asociaciones no se sumen al proceso es por falta de interés, y por ver que no podrán obtener nada para su asociación".

No siempre las entidades se han autoexcluido de los procesos basados en la lógica extensiva, sin embargo, en el caso de Callús, por ejemplo, éstas han sido las más activas en el momento de presentar propuestas que luego han sido sometidas a la votación popular.

Las entrevistas y discusiones en el marco del grupo de aprendizaje también nos permiten detectar tres tendencias claras con respecto al perfil sociodemográfico de los participantes: primero, un equilibrio importante en la representación de hombres y mujeres; segundo, una tendencia significativa a la sobrerrepresentación de las personas adultas mayores en detrimento de las más jóvenes; y tercero, una marcada subrepresentación del colectivo de inmigrantes. De nuevo, El Figaró puede ser presentado como una excepción con respecto a las dos tendencias más negativas que acabamos de señalar.

Los datos no sólo son precarios para el análisis del perfil de los participantes, sino que, además, ninguno de los Ayuntamientos dispone de datos sobre el grado de conocimiento de los Presupuestos Participativos entre el conjunto de la población, con lo cual, cualquier valoración al respecto resultaría excesivamente arriesgada, aunque en el marco del Grupo de Aprendizaje los técnicos de participación reconocen que la comunicación del proceso es uno de los mayores retos que deben enfrentar. 


\section{Impactos en las decisiones presupuestarias}

El carácter vinculante o consultivo de la participación ciudadana es uno de los temas que más polémica política suscita. Sin embargo, nuestro marco jurídico no permite delegar el poder vinculante de toma de decisiones presupuestarias a ningún órgano externo al propio Ayuntamiento. Por lo tanto, más allá de si las decisiones deberían ser jurídicamente vinculantes o no, el debate pertinente es si éstas tienen consecuencias políticas claras: si efectivamente influyen en las decisiones que toman los gobiernos ( $y$ que deben aprobar los Plenos Municipales) y si, una vez formuladas las propuestas ciudadanas, éstas obtienen respuesta institucional (Font y Blanco, 2006).

Resulta difícil evaluar este aspecto en aquellos casos donde la participación se orienta hacia la formulación de propuestas para ser incluidas en el PAM y no directamente en el presupuesto municipal, en el sentido que el hecho que se incorporen en el PAM no garantiza que se vayan a ejecutar. Mataró y Mollet se encuentran en esta situación. Por la misma razón, en estos casos la ciudadanía encuentra muchas más complicaciones para hacer un seguimiento y balance del grado de ejecución de sus propuestas.

En cambio, podemos concluir que, allí donde los procesos participativos se orientan explícitamente a formular propuestas de gasto (y más concretamente, de inversión), los impactos en la toma de decisiones presupuestarias son claros. Los procedimientos de aprobación de propuestas e inclusión en el presupuesto municipal varían en función de las experiencias. En algunas, como Callús o Sant Andreu de la Barca, la partida presupuestaria prevista debe asignarse a un solo proyecto, aquel que resulte ganador en las votaciones finales. En otras experiencias, en cambio, no existe un límite de propuestas, sino simplemente un montante económico determinado, de manera que se aprueban tantas propuestas como recursos económicos existan.

A pesar de que en algunos casos se relatan dificultades económicas y técnicas para implementar algunas de las propuestas incluidas en el presupuesto, éste es, sin duda uno de los aspectos más positivos de las experiencias de Presupuestos Participativos en la provincia de Barcelona. Así lo expresan sus responsables políticos y técnicos:

Concejal de participación: "Es uno de los proyectos que da más prestigio porque son cosas que se ven en la calle: cuando se instalan o mejoran los alumbrados... y se ve en un año. Sirve para las personas que han participado y para acercar a más gente".

Concejal de participación: "Cuando se vieron los resultados la gente dijo que en la segunda edición iba a participar porque se vio que lo que se había aprobado en las jornadas se terminó haciendo en la calle...".

Técnica de participación: "Cuando el siguiente año ves el PAM y identificas tu propuesta entonces es cuando la gente va ganando confianza en el proceso. La gente que

138 participa en una edición sigue participando". 
Como punto culminante del proceso participativo, la mayoría de experiencias prevén algún mecanismo de devolución de resultados por parte del Ayuntamiento hacia la ciudadanía: la presentación de resultados en los Consejos Territoriales y/o Sectoriales o en una Comisión de Seguimiento de los Presupuestos Participativos; el envío de cartas informativas a los participantes; la notificación de resultados a través de boletos informativos o Internet; o varios de estos mecanismos simultáneamente. En algunos casos, los Consejos o la Comisión de Seguimiento tienen asignada la función de seguimiento de la implementación de las propuestas, mientras que en otros es la propia concejalía de participación quien asume esta función de fiscalización, informando, en cualquier caso, a los órganos participativos, al Pleno Municipal y/o a la Junta de Gobierno.

\section{Impactos en la cultura participativa}

¿Hasta qué punto la práctica de los Presupuestos Participativos se ve acompañada de procesos de cambio cultural en los niveles político, técnico y ciudadano? Sin duda, el hecho que la mayoría de experiencias sean tan recientes limita el alcance de cualquier proceso de cambio cultural. Sin embargo, según la propia interpretación de las personas entrevistadas, existen algunos indicios, más o menos evidentes, de tales procesos de cambio.

Algunas personas entrevistadas, por ejemplo, observan que la participación ciudadana ha ido en aumento en las distintas ediciones del presupuesto participativo, lo cual guarda relación, según ellas, con la evidencia que la participación tiene consecuencias tangibles. El caso de Mollet nos permite ilustrar con claridad esta evolución (Gráfico 2).

\section{GRÁFICO 2}

Número de propuestas ciudadanas en los Presupuestos Participativos en el municipio de Mollet

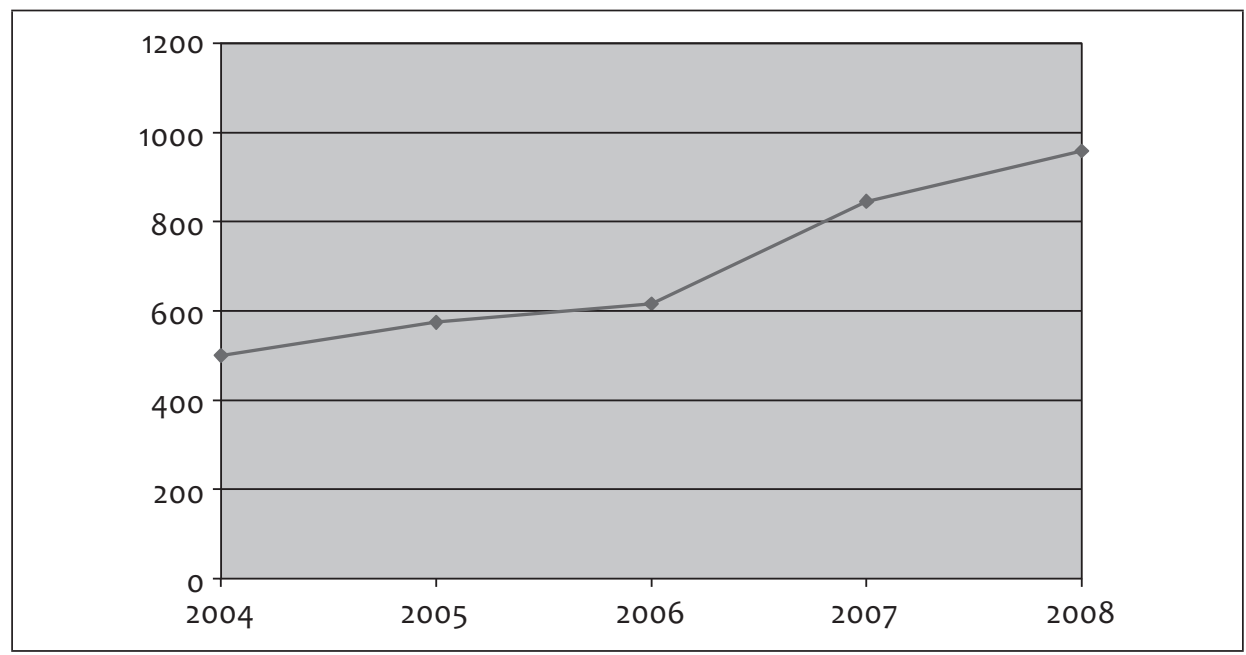

Fuente: Elaboración propia a partir de las informaciones facilitadas por el Ayuntamiento de Mollet. 
Otras destacan cómo los propios técnicos/as municipales muestran señales de aprendizaje y reconocimiento del valor de la participación ciudadana para su actividad cotidiana de gestión. A pesar de que persisten muchas resistencias en este sentido, algunas de las personas entrevistadas sostienen que:

Técnica de participación: "Hay departamentos como el de Urbanismo donde se ha visto que la participación es muy importante; se hizo una plaza sin participación y se tuvo que volver a hacer porque la gente no estaba nada contenta".

Técnica de participación: "Los primeros años de la experiencia fueron muy duros, enviabas propuestas [a los otros departamentos] y los técnicos pasaban. Ahora ya no; todo el mundo sabe lo que se tiene que hacer".

Concejal de participación: "Las otras áreas se están dando cuenta que si hacen un proceso de participación le dedicaran tiempo pero se ganará en tiempo".

Por último, también en un plano político se destaca que la participación ciudadana tiene un efecto contagioso:

Técnica de participación: "Este año nos han pedido procesos para todo [los otros departamentos]. Ya no somos nosotros quienes tenemos que ir detrás suyo".

Hasta qué punto tales tendencias se consolidaran y/o se extenderán es una cuestión que sólo futuras investigaciones podrán vislumbrar.

\section{SIINTESIS Y CONCLUSIONES}

El análisis realizado de las experiencias de Presupuestos Participativos en la provincia de Barcelona nos permite observar las siguientes tendencias generales en relación a los parámetros de evaluación utilizados.

Primero, se trata de procesos que acostumbran a ocupar una posición institucional periférica, en el sentido que son liderados por concejalías de participación que acostumbran a tener un peso institucional escaso dentro de la estructura políticoadministrativa municipal. Sólo en algunos casos se observa una situación de co-liderazgo con la alcaldía o de coordinación con otras áreas de gobierno, pero ni tan sólo en estos casos existen evidencias que nos permitan afirmar que los Presupuestos Participativos sean asumidos transversalmente por el conjunto de los respectivos Ayuntamientos. En definitiva, la falta de un compromiso político generalizado dentro de la estructura de gobierno puede actuar como un fuerte limitador del alcance transformador de estas experiencias.

Segundo, las reglas del juego marcan importantes límites a la capacidad decisoria 140 de la ciudadanía, a través de vías distintas. En algunos casos, porque se excluye del 
debate la estimación de los costes de las propuestas ciudadanas y su encaje en un presupuesto que, por definición, dispone de recursos escasos. Tal ejercicio de priorización presupuestaria, en estos casos, continúa siendo una prerrogativa institucional, lo cual nos lleva a dudar de que este tipo de procesos, por más que lo pretendan, puedan calificarse, efectivamente, como Presupuestos Participativos. En el resto de los casos, la participación se restringe al capítulo de inversiones, excluyéndose otros aspectos del gasto y de los ingresos, aunque ésta no es ninguna particularidad de las experiencias de Barcelona, sino que se da en la mayoría de las experiencias que conocemos a nivel europeo (Sintomer et al., 2008). Sin embargo, sí que llama poderosamente la atención el escaso porcentaje del presupuesto que se somete a la participación ciudadana, con algunas excepciones dignas de mencionar, como la de El Figaró. Tales límites a la participación se ven reforzados aún más si cabe en otras experiencias por el establecimiento de límites temáticos. Todas estas restricciones podrían influir muy negativamente en la percepción ciudadana que éstas sean experiencias realmente empoderadoras, aunque éste es un aspecto que aquí sólo podemos apuntar.

Tercero, los niveles de participación ciudadana son muy escasos en la mayoría de las experiencias y, además, se producen sesgos representativos muy marcados. Si bien este hecho no es exclusivo de las experiencias de Presupuestos Participativos, ya que se da en otros procesos de participación ciudadana, en alguno de los casos analizados en este estudio vemos cómo los niveles de participación en los presupuestos pueden venir inducidos por unas reglas del juego que privilegian a los miembros de las asociaciones y excluyen o dejan en una posición periférica a la ciudadanía no organizada. En otros casos, éstos son producto de la desigualdad de recursos y de motivaciones políticas de distintos grupos sociales y de la incapacidad de las metodologías para contrarrestar sus efectos en términos de movilización social. También el tamaño del municipio parece influir significativamente en el porcentaje de participación, más alto en los municipios más pequeños. El hecho que las propuestas ciudadanas generen resultados tangibles (y que se visibilice a partir de una buena campaña de comunicación institucional) también parece influir la participación en ediciones posteriores. En cualquier caso, los datos producidos por los Ayuntamientos al respecto son muy precarios, lo cual denota escasa conciencia de la necesidad de evaluar este aspecto.

Cuarto, uno de los aspectos más positivos de las experiencias de Presupuestos Participativos que se incluyen en este estudio es la existencia de impactos claros en la toma de decisiones presupuestarias y, podemos suponer, su reflejo en aspectos más o menos importantes de la configuración urbanística de los municipios. Este aspecto se ve reforzado por el hecho que la mayoría de experiencias adopten mecanismos de seguimiento y control de la ejecución de las propuestas. Sin embargo, en las experiencias en donde la traducción de las propuestas al presupuesto es indirecta, los efectos sobre la toma de decisiones presupuestarias son más difíciles de discernir.

Por último, las entrevistas realizadas nos permiten detectar indicios de cambio en las actitudes políticas de los principales actores locales (políticos, técnicos, asociaciones, ciudadanía) como consecuencia del proceso participativo. Si bien se trata de 
procesos muy recientes y aunque las resistencias culturales continúan pesando mucho sobre este tipo de procesos, algunos indicios nos permiten afirmar que otro de los efectos más significativos de los Presupuestos Participativos son sus consecuencias en términos de cambio cultural, aunque el escaso volumen de la participación limita, necesariamente, los efectos educativos entre la ciudadanía.

Hasta aquí hemos sintetizado las tendencias compartidas por todas las experiencias en mayor o menor intensidad. Pero, si afinamos el análisis comparado, ¿existen tendencias diferenciadas significativas? ¿De qué dependen?

La elevada homogeneidad política de estos municipios no nos permite contrastar la influencia de esta variable en los rendimientos de las distintas experiencias de participación analizadas, aunque podríamos aventurar que el peso de las candidaturas independientes de orientación política progresista, con un fuerte compromiso ideológico respecto a la participación popular, explica en parte la potencia de algunas experiencias como Callús y El Figaró. Sea como sea, las experiencias lideradas por el PSC son muy desiguales entre sí.

Sin duda, sin embargo, también interviene aquí el tamaño de los municipios. Así, contrastando lo observado por otros estudios (Ganuza y Gómez, 2008), podemos afirmar que, en los municipios pequeños, la coordinación de las distintas áreas de gobierno alrededor de los Presupuestos Participativos es más evidente; los porcentajes del presupuesto destinados a la participación son mayores; y los porcentajes de participación ciudadana son ligeramente más altos. Aparentemente, también en estos municipios es donde las decisiones son más visibles para la población y donde los impactos sobre la cultura participativa son más significativos. Ahora bien, de nuevo hay que remarcar que entre los municipios más grandes hay una diversidad notable de casos, lo cual nos lleva a concluir que no cabe ningún determinismo con respecto a las posibilidades de éxito de este tipo de procesos en municipios grandes.

¿Qué lecciones podemos extraer de este análisis? En negativo, podemos concluir que las experiencias analizadas presentan limitaciones demasiado importantes como para esperar de ellas efectos transformadores significativos en las dimensiones identificadas por la literatura (educación democrática, generación de capital social, mejora de las políticas, inclusión social). A pesar de ello, es posible identificar buenas prácticas en cada uno de los parámetros señalados: el liderazgo político de las experiencias de Arenys de Mar o de El Figaró y la asunción transversal del proceso en un gran Ayuntamiento como el de Terrassa; la amplitud de los márgenes de decisión de El Figaró; los altos niveles de participación logrados en casos como Callús, Parets o Mataró, a pesar del diferente tamaño de estos municipios y de las distintas lógicas organizativas que siguen; los elevados impactos de la participación en experiencias como Barberà del Vallès o Sant Andreu; o la evidencia de cambios culturales más o menos significativos en la mayoría de las experiencias.

El artículo ha pretendido identificar algunas variables clave que refuerzan la ca142 pacidad transformadora de procesos como los Presupuestos Participativos. No se 
ha entrado a valorar, sin embargo, si efectivamente quien impulsa políticamente estos procesos pretende generar o no grandes transformaciones político-culturales, sino simplemente si estos procesos cumplen las condiciones teóricamente necesarias para satisfacer las expectativas que la literatura académica (y ciertos discursos políticos) depositan en ellos. Conocer estas variables permite identificar retos de mejora para aquellos actores implicados en el impulso y la gestión de los proceso de participación. La experiencia del Grupo de Aprendizaje en que se basa este estudio ha pretendido contribuir a la discusión sobre las estrategias que nos acercan a estos objetivos.

\section{REFERENCIAS BIBLIOGRÁFICAS Y DOCUMENTALES}

Aberts, R. (2001), Inventing local democracy: grassroots politics in Brazil. Boulder: Lynne Rienner Publishers.

Arnstein, Sh. (1969), “A Ladder of Citizen Participation”, Journal of the American Institute of Planners, 35(4): 216-24.

Avritzer, L. y Navarro, Z., orgs., (2003), A inovação democrática no Brasil: o orçamento participativo. São Paulo: Cortez.

Baiocchi, G. (2003), Radicals in Power. The Worker's Party (PT) and experiments in urban democracy in Brazil. Nueva York: Zed Books.

Barnes, M., Newman, J. y Sullivan, H. (2007), Power, participation and political renewal. Cases studies in public participation. Bristol: The Policy Press.

Blanco, I. (2003), “Presupuestos participativos en Rubí: innovación, límites y retos de una experiencia pionera”, en E. Ganuza y C. Álvarez, coords., Democracia y Presupuestos Participativos. Barcelona: Icaria.

Castellà, C. y Jorba, L. (2008), "Evaluación de las experiencias participativas en la gestión local de Cataluña: promesas y amenazas”, Gestión y Análisis de Políticas Públicas, 32: 79-98.

Christensen, K. (1999), Cities and Complexity: Making Intergovernmental Decisions. Londres: Sage.

Clarke, M. y Stewart, J. (1997), Handling the Wicked Issues: A Challenge for Government. Birmingham: Institute of Local Government Studies.

Dalton, R. (2004), Democratic challenges, democratic choices: the erosion of political support in advanced industrial democracies. Oxford: Oxford University Press.

Del Pino, E. y Colina, C. (2003), Las nuevas formas de participación en los gobiernos locales. Madrid: Fundación Alternativas.

Fishkin, J. (1995), The Voice of the People. Public Opinion and Democracy. New Haven: Yale University Press.

Font, J. (2001), Ciudadanos y Decisiones Públicas. Barcelona: Ariel.

Font, J. y Blanco, I. (2006), Polis, la ciudad participativa. Barcelona: Diputación de Barcelona. En línea: <http://www.diba.cat/participacio/fitxers/publicacions_papers/ ogpapers_cast.pdf> (consulta: 1 mayo 2010).

Fung, A. (2004), Empowered participation: reinventing urban democracy. Princenton: Princenton University Press. 
Fung, A. (2006), "Varieties of participation in complex governance", Public Administration Review, 66: 66-75.

Ganuza, E. y Álvarez, C., coords., (2003), Democracia y Presupuestos Participativos. Barcelona: Icaria.

Ganuza, E. (2003), “Los presupuestos participativos en Córdoba”, en E. Ganuza y C. Álvarez, coords., Democracia y Presupuestos Participativos. Barcelona: Icaria.

Ganuza, E. (2005), “Democracia y nuevos horizontes: emergencia y límites de los presupuestos participativos en España”, Acciones e investigaciones sociales, 20: 5-39.

Ganuza, E. y Gómez, B. (2008), Control democrático y presupuestos participativos en España. Madrid: Fundación Alternativas, EP38/2008.

Haus, M., Heinel, H. y Stewart, M. (2005), “Introduction”, en M. Haus, H. Heinelt y M. Stewart, eds., Urban governance and democracy: Leadership and community involvement. Londres: Routledge.

Smith, I., Lepine, E. y Taylor, M., eds., (2007), Disadvantaged by where you live? Neighbourhood governance in contemporary urban policy. Bristol: The Policy Press.

Nylen, W. R. (2002), "Testing the Empowerment Thesis: The Participatory Budget in Belo Horizonte and Betim, Brazil", Comparative Politics, 34(2): 127-145.

Nylen, W. R. (2003), Participatory democracy versus elitist democracy: lessons from Brazil. Londres: Palgrave Macmillan.

Osborne, D. y Gaebler, T. (1994), La reinvención del gobierno. La influencia del espiritu empresarial en el sector público. Barcelona: Paidós.

Papadopoulos, Y. y Warin, Ph. (2007), “Are innovative, participatory and deliberative procedures in policy making democratic and effective?", European Journal of Political Research, 46(4): 445-472.

Pares, M., coord., (2009), Participación y calidad democrática. Evaluando las nuevas formas de democracia participativa. Barcelona: Ariel.

Pires, V. y Pineda, C. (2008), "Presupuesto participativo: una tipología para superar los límites de las definiciones demasiado amplias o restrictivas", Revista de Estudios de la Administración Local y Autonómica, 308: 207-242.

Putnam, R. (2000), Solo en la bolera. Barcelona: Galaxia-Gutemberg.

Sintomer, Y. (2005), “Los presupuestos participativos en Europa: retos y desafíos", Revista del CLAD Reforma y Democracia, 31: 63-92.

Sintomer, Y., Herzberg, C. y Röcke, A. (2008), "Participatory Budgeting in Europe: Potentials and Challenges", International Journal of Urban and Regional Research, 32(1): 164-178.

Subirats, J., Blanco, I., Brugué, Q. et. al. (2001), Experiències de participació ciutadana en els municipis catalans. Barcelona: Escola d'Administració Pública de Catalunya.

Waagenar, H. (2007), "Governance, complexity and democratic participation: how citizens and public officials harness the complexities of neighbourhood decline", The American Review of Public Administration, 37(1): 17-50.

Wainwright, H. (2006), Cómo ocupar el Estado. Barcelona: Icaria.

Recibido: 20 de mayo de 2010

144 Aceptado: 7 de septiembre de 2010 